\title{
Treatment of acne with a combination of propolis, tea tree oil, and Aloe vera compared to erythromycin cream: two double-blind investigations
}

This article was published in the following Dove Press journal: Clinical Pharmacology:Advances and Applications

\section{$\checkmark$ Mazzarello \\ MG Donadu \\ M Ferrari \\ G Piga \\ D Usai \\ S Zanetti \\ MA Sotgiu}

Skinlab, Department of Biomedical Sciences, University of Sassari, Sassari, Italy
Correspondence: $\vee$ Mazzarello Skinlab, Department of Biomedical Sciences, University of Sassari, Viale San Pietro 43, 07 100 Sassari, Italy

Tel +3979228536

Fax +3979228520

Email vmazza@uniss.it
Introduction: Antibiotics that suppress Propionibacterium acnes are the standard treatment for acne but are becoming less effective, due to the appearance of antibiotic-resistant strains. Many plants are known to have innate antimicrobial action and can be used as alternatives to antibiotics; thus, it is necessary to prove their effectiveness in vivo. This study aimed to evaluate the anti-acne efficacy of a new cream based on three natural extracts, comparing it to erythromycin cream and placebo. Patients and methods: Sixty patients with mild to moderate acne vulgaris were randomly divided into three groups: treated with cream containing $20 \%$ propolis, $3 \%$ "tea tree oil", and $10 \%$ "Aloe vera" (PTAC) $(\mathrm{n}=20)$; or with $3 \%$ erythromycin cream (ERC) $(n=20)$; or with placebo $(n=20)$. At baseline, after 15 and 30 days, investigators evaluated response to treatment by counting acne lesions through noninvasive measurements and macro-photography.

Results: All the clinical and instrumental values studied were statistically different from placebo except for sebometry, pHmetry, and erythema index values, measured on healthy skin. Unlike in the placebo group, papular and scar lesions showed high erythema reduction after 15 and 30 days of PTAC and ERC application.

Conclusion: The PTAC formulation was better than ERC in reducing erythema scars, acne severity index, and total lesion count.

Keywords: phytotherapy, Aloe barbadensis, Melaleuca alternifolia oil, propolis, noninvasive analysis, antibiotic resistance

\section{Introduction}

Acne is a follicular skin disease that mainly affects the pilosebaceous unit of face, neck, and trunk and is characterized by inflammatory (papules, pustules, nodules, and cysts) and non-inflammatory lesions (seborrhea and comedones) and scarring. ${ }^{1}$

Although in many patients, acne can be limited to a couple of papules or comedones, serious illness can lead to disfiguring scars on the face. Despite not being a life-threatening disease, acne can have severe psychosocial consequences causing low self-esteem, social isolation, and depression. ${ }^{2}$

Many factors are known to contribute to the pathogenesis of acne: increased production of sebum, anomalous keratinization of the pilosebaceous canal, bacterial colonization (Propionibacterium acnes, Staphylococcus aureus, Staphylococcus epidermidis are the most important pathogens), and the production of inflammatory factors. ${ }^{3,4}$

Each type of acne therapy is based on the specific clinical phase of the disease. Thus, even if a systemic therapy is set up, it is often useful to prescribe a topical 
treatment that might be more effective and have fewer side effects, improving specific aspects of symptomatology and eventually reducing unwanted skin reactions.

Most patients present with mild to moderate comedonal or papulopustular acne; in such patients, topical therapy is the first line of treatment. ${ }^{5}$

The most frequently used topical agents include keratolytics, alpha-hydroxy acids, benzoyl peroxide, retinoids, azelaic acid, and antibiotics. Antibiotics that suppress $P$. acnes are the standard treatment for acne, but are becoming less effective, due to the appearance of antibiotic-resistant strains also described for the $S$. epidermidis and other coagulase-negative staphylococci. ${ }^{6,7}$

For this reason, we are looking for new natural products that can replace, with equal or greater efficacy, the synthetic antibiotics increasingly affected by the phenomena of therapeutic resistance. In previous studies, various natural extracts were used, usually one by one, showing good anti-acne efficacy. This study aims to evaluate the efficacy of a new cream based on three natural extracts (propolis, "tea tree oil", and "Aloe vera") in treating mild to moderate acne, comparing it to a cream based on $3 \%$ erythromycin and to its vehicle alone (placebo).

\section{Patients and methods Study design}

This single-center, randomized, double-blinded, comparative study enrolled 60 patients of both genders. The study was conducted at the Skinlab, Department of Biomedical Sciences, University of Sassari, Italy, in the winter season.

All patients presented with the following characteristics: age between 14 and 34 years; mild to moderate facial acne vulgaris defined as the maximum number of comedones as well as papules and pustules less than 20 and 50, respectively; the absence of any nodules, cysts, and slight erythematous scarring presence; response to topical treatment with erythromycin in antecedent anti-acne treatments; good health; and no ongoing topical or systemic treatments occurring during the 3 months prior to experiments. ${ }^{8}$

Subjects who were pregnant, lactating, in menopause, with polycystic ovarian syndrome, taking oral contraceptives, with allergic contact dermatitis, and with sensitive skin were excluded from the study.

After meeting inclusion/exclusion criteria, written informed consent was obtained from each participant by the research coordinator.

The patients were randomly divided into three groups of 20 patients each. Group A was treated with a cream containing $20 \%$ propolis extract, $3 \%$ tea tree oil, and $10 \%$ $A$. vera leaf juice (PTAC) as active ingredients.

Group B was treated with a 3\% erythromycin (ERC) cream. Group C (control) used the vehicle without any active ingredients (placebo). The three creams (produced by Humana Pharma International spa, Pavia, Italy) have the same characteristics of color, consistency, and package but presented different labels.

The active ingredients present in PTAC cream are products by Kelisema srl (Tavernerio, Como, Italy). The propolis contains several flavonoid compounds resulting from the enzymatic hydrolysis of the original plant glycosides; derivatives of cinnamic, benzoic, and caffeic acids; vitamins; minerals ( $\mathrm{Zn}, \mathrm{Cu}, \mathrm{Mn}, \mathrm{Ca}, \mathrm{Fe}$, etc); resins and waxes. The tea tree oil is composed of terpene hydrocarbons, mainly monoterpenes, sesquiterpenes, and their associated alcohols. A. barbadensis leaf juice is mainly composed of polysaccharides containing glucose and mannose; minor components having important biological activity are phytosterols, vitamins, enzymes, phosphorylated monosaccharides, aminoacids, and minerals.

Volunteers recruited for the study were asked to use the product twice a day, in the morning and in the evening as any common anti-acne treatment for a total of 30 days. During the test, volunteers did not use other products for acne treatment to avoid a possible overlapping of effects.

\section{Instrumental and clinical evaluation}

At the time of inclusion ( $\mathrm{t} 0$ ), after 15 days (t15), and after 30 days ( $\mathrm{t} 30$ ), investigators evaluated the cutaneous status of volunteers, performing during each visit a clinical observation, instrumental measurements, and macro-photography.

Instrumental measurements aimed at evaluating physical cutaneous indexes such as the quantity of sebum using the Sebumeter SM 825 (Courage+ Khazaka Electronic $\mathrm{GmbH}$, Cologne, Germany), skin surface $\mathrm{pH}$ using the Skin-pH-Meter PH 900 (Courage+ Khazaka Electronic $\mathrm{GmbH}$ ), and cutaneous erythema index using Mexameter MX16 (Courage+ Khazaka Electronic GmbH). The sebometric and $\mathrm{pH}$-metric values were taken on skin areas without acne lesions. The amount of erythema was evaluated on healthy skin, on papular lesions, and on cicatricial erythematous lesions. The experimenters performed instrumental tests on the cheek area, chosen randomly for each volunteer, adopting three measurements for each probe - in contiguous healthy areas or on different inflamed lesions - subsequently calculating the mean value. The analyzed areas have always been the same for each volunteer during the different examinations. 
At the beginning and at the end of the treatment, experimenters took macro-photography (Canon G10) of the face of the volunteers, focusing the left and right side of the face and the forehead.

Clinical examination evaluated the number of comedones $(\mathrm{CN})$, papules (PPN), and pustules (PSN) located on the face. In order to analyze subjective evaluations made by the investigator dermatologist for each parameter, the total of scores for each considered lesion was calculated. Both the total lesion count (TLC) and the acne severity index (ASI) were used to determine the effectiveness of the acne severity treatment. TLC was calculated as: TLC $=\mathrm{PPN}+\mathrm{PSN}+\mathrm{CN}$. The ASI was calculated as: $\mathrm{ASI}=\mathrm{PPN}+(\mathrm{PSN} \times 2)+(\mathrm{CN} / 4)$.

During the first examination, the number of lesions and ASI and TLC were considered to be $100 \%$, and any decrease of lesions was calculated accordingly and regarded as improvement percentage. The mean value of these improvement percentages was calculated for each group of patients and was used for statistical analysis.

\section{Statistical analysis}

All results were compared to each baseline measurement by paired $t$-tests or with a non-parametric test (Wilcoxon signed-rank test), and when difference in mean values did not have normality characteristics, they were verified by using Shapiro-Wilk test. All statistical tests were two-tailed tests and $P$-values $\leq 0.05$ were considered statistically significant. All data analyses were performed using an SPSS statistical package. All data were submitted as mean $\pm \mathrm{SD}$, and beyond measured value, differences vs baseline were reported.

\section{Ethical approval}

Approval from the Ethics Committee/Institutional Review Board of the Department of Biomedical Sciences, University of Sassari, Sassari, Italy, was obtained and the study was conducted in complete agreement with the principles of the Declaration of Helsinki.

\section{Results}

The demographic characteristics of the patients are reported in Table 1. There were no significant differences related to these characteristics among the three groups $(P=0.0105)$, confirming the success of randomization. All patients completed the study.

\section{Instrumental and clinical evaluation}

The instrumental and clinical results obtained in the study are shown in Figure 1, Tables 2 and 3. All the clinical and
Table I Demographic characteristics of patients

\begin{tabular}{|l|l|l|l|}
\hline & Placebo & PTAC & ERC \\
\cline { 2 - 4 } & $(\mathbf{n = 2 0})$ & $\mathbf{( n = 2 0 )}$ & $\mathbf{( n = 2 0 )}$ \\
\hline Male & $8(40 \%)$ & $5(25 \%)$ & $6(30 \%)$ \\
Female & $12(60 \%)$ & $15(75 \%)$ & $14(70 \%)$ \\
Age, years (mean \pm SD) & $24 \pm 6.14$ & $27 \pm 7.44$ & $23 \pm 5.06$ \\
Acne severity index & $25.9 \pm 11.4$ & $31 \pm 11.4$ & $27.8 \pm 10.9$ \\
\hline
\end{tabular}

Abbreviations: PTAC, propolis, tea tree oil, and Aloe vera cream; ERC, $3 \%$ eritromicin cream.

instrumental values studied were statistically different from the placebo group, but the sebometry, pHmetry, and erythema index values, measured on healthy skin, did not undergo statistically significant changes during the treatment in the three study groups.

Unlike to what happened in patients who used the placebo, papular and scar lesions showed high reduction in their erythema after 15 and 30 days of PTAC and ERC application (Table 2, Figure 1C, D). The PTAC formulation was better than ERC in reducing erythema scars, thus speeding up healing time, as early as the first 15 days of treatment. The PTAC was more effective in reducing erythema scars even at t30 than ERC, and this intergroup difference was statistically significant $(P=0.003)$ (Figure 1C). No difference between the two active products in reducing papular erythema was reported (t15: $P=0.361 ; \mathrm{t} 30: P=0.210$ ) (Figure 1D).

The comparison between the clinical scores obtained at the time of inclusion, after 15 and after 30 days of treatment allowed to define the two creams with active ingredients as effective when compared to placebo in decreasing the acne lesions in subjects participating in the study (Table 3, Figure 1A, B).

PTAC was more effective than ERC in reducing ASI and TLC. The ASI in the PTAC group has been significantly reduced by $31.6 \%$ and $66.7 \%$ while in the ERC group it decreased by $27.1 \%$ and by $49.7 \%$, respectively, after 15 and 30 days of treatment. This difference in PTAC efficacy vs ERC was significant $(P=0.0368)$ after 30 days. Mean TLC value in the PTAC group significantly decreased by $33.56 \%$ and by $63.7 \%$, while in the ERC group significantly decreased by $23.6 \%$ and $46.5 \%$, respectively, after 15 and 30 days. The efficacy of TLC treatment was higher for the PTAC group compared to the ERC group after 30 days $(P=0.001)$ of treatment (Figure 1A).

In PTAC and ERC patient groups, the number of inflammatory and non-inflammatory lesions was significantly reduced in comparison to baseline values at 15 and 30 days (Table 3 ). Only the percentage of PPN in PTAC group, at t30, was higher than patients who received ERC $(P=0.0382)$ (Figure 1B). 
A

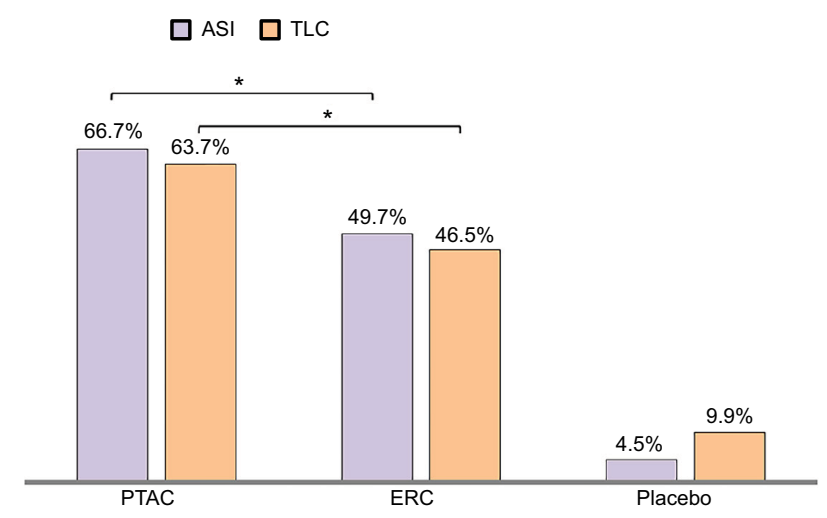

C

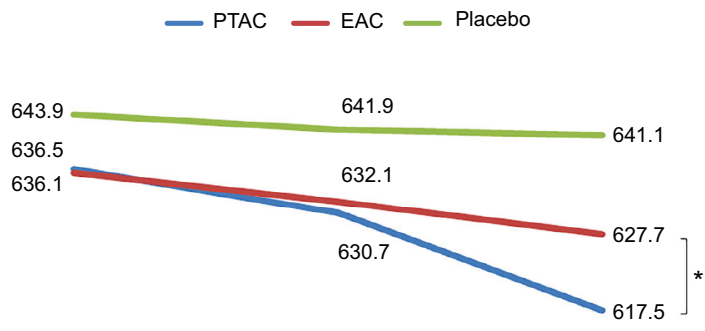

t0 t15
B

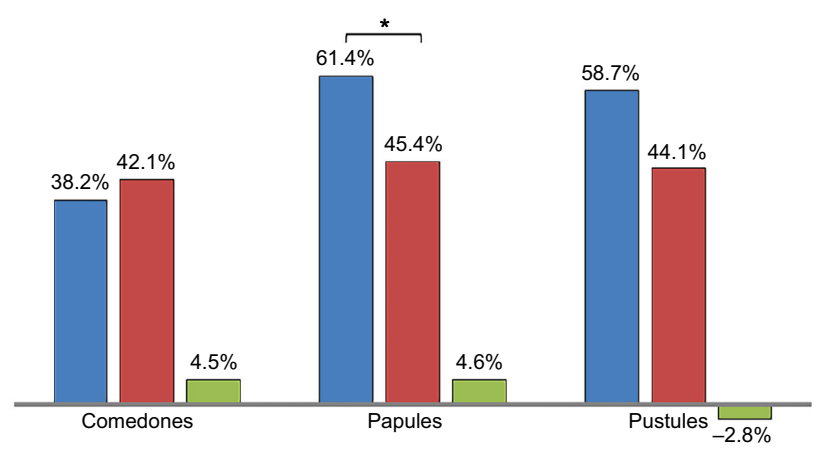

D

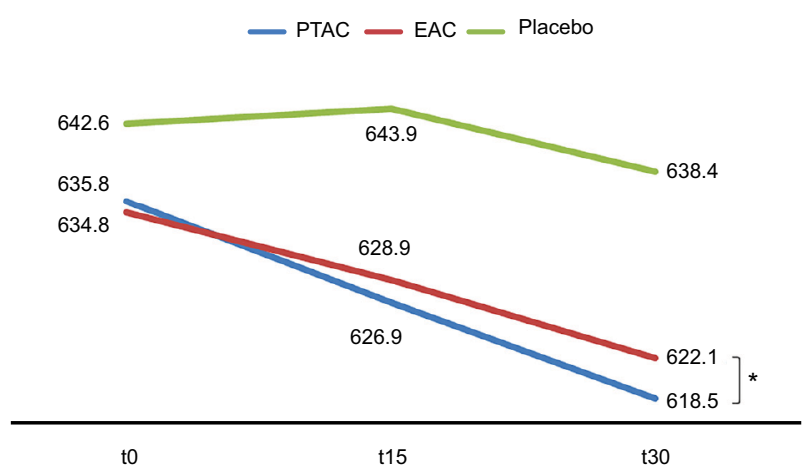

Figure I The instrumental and clinical results obtained in the study of three formulations for the reduction of lesions and erythema.

Notes: (A) Efficacy of PTAC, ERC and placebo in TLC and ASI after 4 weeks. (B) Efficacy of PTAC, ERC and placebo in the reduction of different types of lesions after 4 weeks. (C) Erythema index of cicatricial lesions. (D) Erythema index of papular lesions. $t=$ time in days. ${ }^{*} P \leq 0.05$.

Abbreviations: PTAC, propolis, tea tree oil, and Aloe vera cream; ERC, 3\% eritromicin cream; ASI, acne severity index; TLC, total lesion score.

\section{Discussion}

The ideal treatment for acne should be topical, effective, and well tolerated by patients. The products on the market use predominantly antibiotics or irritant products to be used in the evening to avoid sun exposure.

Antibiotics are becoming less effective due to the emergence of resistant strains. Antibiotic resistance in P. acnes and S. epidermidis has been rising steadily since the 1980 s. In one analysis covering 10 years in the UK, resistant bacteria carriage was noticed in more than $50 \%$ of patients who had acne and who were treated with antibiotics, with most patients carrying multiple different resistant strains on different parts of their body. Similar trends have been reported in several other industrialized nations..$^{9,10}$

Other products for acne treatment have poor compliance by the patient due to irritating effects that are not always appreciated.

These and other concerns, including costs, highlight the need for safer, effective, and cheapest approaches, including those offered by herbal medicine.
The antimicrobial effects of plant extracts are particularly intriguing in the context of the growing problem of antibiotic resistance. Many plants are known to have innate antimicrobial and anti-inflammatory properties, and plant extracts may help slowing down the development of resistant organisms when used as alternatives to antibiotics.

Herbal and botanically derived remedies are increasingly popular in the treatment of acne and several authors have proven their effectiveness. ${ }^{11-20}$

Based on this reasoning we have tested the efficacy of a new product, formed by the association of three natural antibacterial substances that have never been tested together previously in vivo.

This product contains propolis $20 \%$, tea tree oil $3 \%$, and A. vera $10 \%$, which were chosen because have been proven antibacterial and anti-inflammatory properties.

Several studies have demonstrated the important antibacterial actions of propolis, which demonstrated much greater activity toward Gram-positive bacteria than Gram-negative 
Table 2 Efficacy of PTAC (propolis, tea tree oil, and Aloe vero cream) and ERC ( $3 \%$ eritromicin cream and placebo) in the reduction of biophysical parameters

\begin{tabular}{|c|c|c|c|}
\hline & to & $\mathbf{t} \mathbf{5}$ & t30 \\
\hline \multicolumn{4}{|c|}{ Sebumeter measures } \\
\hline PTAC & $47(27.8)$ & $40.8(20.3)$ & $44.8(22.9)$ \\
\hline ERC & $43.4(23.6)$ & $42.0(16.2)$ & $44.4(16.7)$ \\
\hline Placebo & $36.6(17.3)$ & $35.2(17.3)$ & $40.3(18.7)$ \\
\hline \multicolumn{4}{|c|}{ pHmeter measures } \\
\hline PTAC & $4.99(0.24)$ & $5.02(0.22)$ & $5.02(0.18)$ \\
\hline ERC & $5.03(0.17)$ & $5.00(0.16)$ & $5.02(0.09)$ \\
\hline Placebo & $5.06(0.34)$ & $5.00(0.33)$ & $5.03(0.32)$ \\
\hline \multicolumn{4}{|c|}{ Erythema index of perilesional skin } \\
\hline PTAC & $586.4(13.6)$ & $586.6(16.2)$ & $584.6(17.9)$ \\
\hline ERC & $581.5(14.9)$ & $581.9(12.5)$ & $585.4(10.0)$ \\
\hline Placebo & $582.6(8.6)$ & $581.8(6.9)$ & $582.1(17.4)$ \\
\hline \multicolumn{4}{|c|}{ Erythema index of scars } \\
\hline PTAC & $636.5(20.5)$ & $630.7(6.5)^{*}$ & $617.5(10.0)^{* * *}$ \\
\hline ERC & $636.1(16.0)$ & $632.1(15.6)$ & $627.7(14.9)^{* * *}$ \\
\hline Placebo & $643.9(23.6)$ & $641.9(13.4)$ & $641.1(13.0)$ \\
\hline \multicolumn{4}{|c|}{ Erythema index of papules } \\
\hline PTAC & $635.8(14.5)$ & $626.9(16.7)^{* *}$ & $618.5(19.0)^{* * *}$ \\
\hline ERC & $634.8(10.4)$ & $628.9(10.9)^{* *}$ & $622.1(10.5)^{* * *}$ \\
\hline Placebo & $642.6(11.0)$ & $643.9(18.3)$ & $638.4(8.7)$ \\
\hline
\end{tabular}

Notes: The data are presented as mean (SD) difference in sebumetry, pHmetry, and erythema index values from baseline to days 15 and $30 . * P \leq 0.05, * * P \leq 0.01$, $* * * P \leq 0.001$. $t=$ time in days.

Abbreviations: PTAC, propolis, tea tree oil, and Aloe vera cream; ERC, 3\% eritromicin cream.

ones. ${ }^{21}$ These antibacterial effects could be due to the synergistic activity of the numerous compounds present in propolis, such as flavonoids, caffeic acid, benzoic acid, and cinnamic acid. These compounds probably act on the microbial membrane or cell wall site, causing functional and structural damages. ${ }^{22}$ Synergism between the propolis and some antibacterial agents has been observed. ${ }^{23}$ Antibacterial activity of propolis is bacteriostatic and can be bactericidal at higher concentrations. ${ }^{24}$ Intriguingly, propolis also displays anti-inflammatory properties in both acute and chronic inflammatory processes, and this is principally due to its large content of polyphenol compounds. ${ }^{25}$ Its anti-acne efficacy has not been proven yet. In our preparation, we used propolis $10 \%$ to reduce the adverse risks described by other authors. ${ }^{26}$

The tea tree oil contains several monoterpenes $(80 \%-$ 90\%) and the most abundant of these is terpinen-4-ol, which makes up to at least $30 \%$ and has an important role in the antimicrobial activity of this essential oil. ${ }^{27}$ Six comparative studies ${ }^{11,14,16,19,20,28}$ tested tea tree oil in the treatment of mild to moderate acne; of them, three were double-blinded. ${ }^{11,16,20}$ These six studies evaluated products containing $0.1 \%-5 \%$ tea tree oil and found that the number of lesions was reduced,
Table 3 Efficacy of PTAC (propolis, tea tree oil, and Aloe vera cream) and ERC ( $3 \%$ eritromicin cream and placebo) in the reduction of different types of lesions

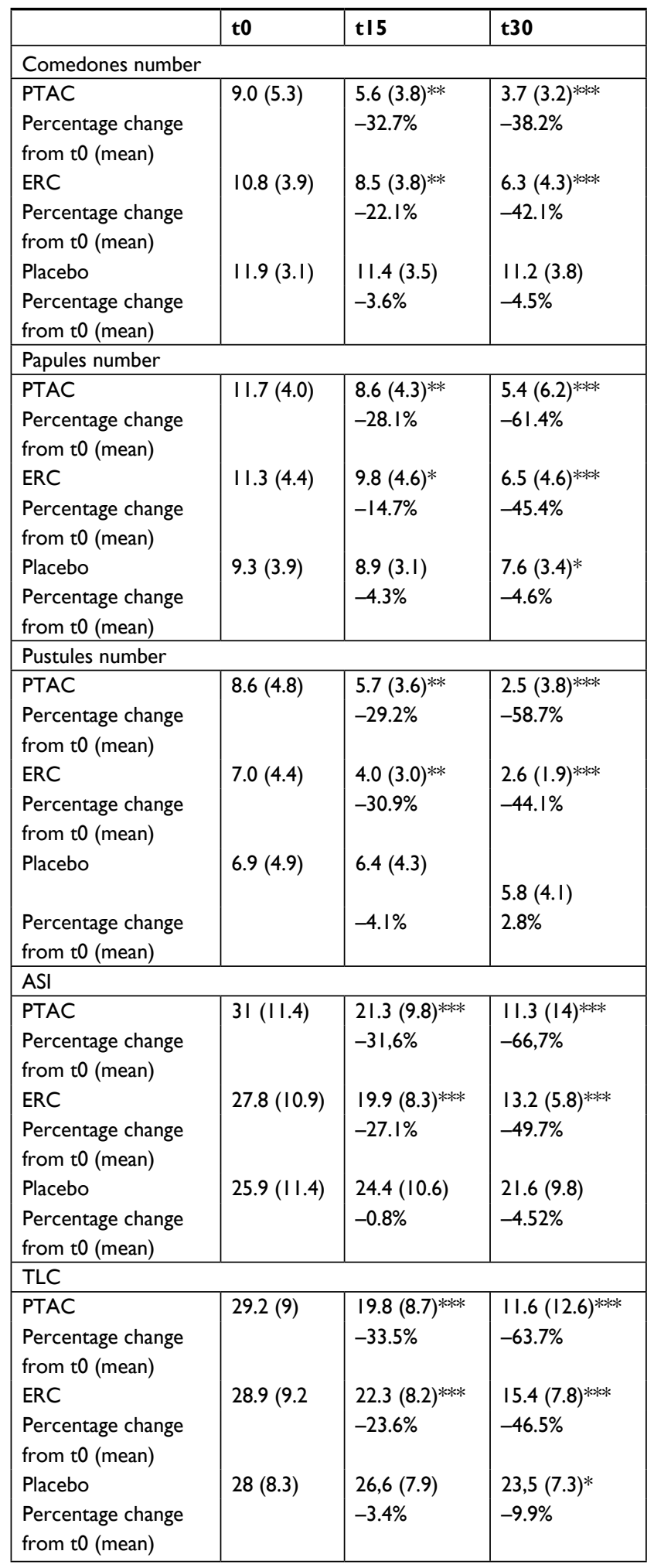

Notes: Mean (SD) difference and percent changes in the numbers of comedones, papules, pustules, acne severity index (ASI, and total lesion score (TLC from baseline to days 15 and 30 . $* P \leq 0.05, * * P \leq 0.01, * * * P \leq 0.00 \mathrm{I}$. $\mathrm{t}=$ time in days.

Abbreviations: PTAC, propolis, tea tree oil, and Aloe vera cream; ERC, 3\% eritromicin cream. 
with reductions ranging from $23.7 \%$ to $62.1 \%$ after products were applied for 4-8 weeks. In these studies, tea tree oil was used alone or in association with other plant extracts such as Ramulus mori and lavender oils. The average minimal inhibitory concentration of tea tree oil against $P$. acnes and S. epidermidis was in the range between $0.31 \%$ and $0.63 \%$ $\mathrm{v} / \mathrm{v}^{29}$ The minimum bactericidal concentration, required to eliminate $P$. acnes, was $0.5 \% \mathrm{v} / \mathrm{v}^{30}$

In our study, we used tea tree oil at $3 \%$ concentration, the range considered as anti-acne by other authors and which is well above the concentration needed for its in vitro activity.

$A$. vera has many therapeutic properties including antiinflammatory and bacteriostatic activities. In the literature, there were two studies where $A$. vera was used in the treatment of acne. The first is a double-blind study, where the administration of a cream and a drink made from $A$. vera and seven other plant extracts improved acneic lesions compared to placebo group, in which no improvement was noticed. ${ }^{12}$ In another study, a 50\% gel was used in combination with tretinoin, which was significantly more effective in reducing non-inflammatory, inflammatory, and total lesion scores than in control group. ${ }^{31}$

In our study, PTAC was compared to $3 \%$ erythromycin cream as a positive control. The erythromycin was chosen, especially, for its easy availability and tolerability. In recent years, erythromycin, due to its greater resistance to acne treatment, has been replaced by clindamycin. ${ }^{32}$ To be sure that patients did not have resistance problems, we recruited a sample of volunteers who had used the molecule with positive results at least 6-12 months before our test.

All data obtained from both instrumental and the clinical tests, during the use of PTAC, demonstrated the validity of the topical pharmacological formulation under consideration and confirmed the findings in the precedent studies, which showed that natural topical extracts were effective in the clearance of papules and pustules, especially in mild and moderate acne.

In particular, the instrumental study has shown that PTAC does not possess sebum-reducing properties, respected the hydrolipidic film, and did not irritate the healthy skin as it has not changed the superficial sebometry, the $\mathrm{pH}$ and the erythema index.

The sebum normalizing action has been studied because compounds, such as isoflavones, chalcone, and tannin, contained mainly in the propolis, have been reported to be effective in inhibiting 5- $\alpha$ reductase enzymes in vitro. ${ }^{33} \mathrm{We}$ could not observe any results, perhaps because 1-month application or the concentration used was not sufficient to obtain results.

PTAC improved the erythema index of papules and erythematous scars more prominently than ERC, as demonstrated by early action on scar inflammation which, unlike the ERC, improved since the first 15 days. The anti-inflammatory efficacy of the product can be linked to the presence of $A$. vera and propolis. The greatest anti-inflammatory effect had occurred in erythematous scars, probably due to the action of propolis, which is capable of increasing the wound healing rate. ${ }^{34}$ The lower efficacy toward papular erythema may be related to the fact that $A$. vera shows no activity against IL-8 and TNF- $\alpha$ production in $P$. acnes stimulated cultures. ${ }^{35}$

The clinical study showed a greater effectiveness of PTAC in reducing the number of lesions compared to ERC. In fact, PTAC was able to reduce ASI by $68 \%$ and the TLC by $64 \%$ after 30 days of daily use compared to $50 \%$ and $47 \%$, respectively, by ERC. These results are higher when compared to those obtained by other researchers using the single products we tested, even at higher concentrations or in topical association with other plant extracts. The antibacterial and anti-acne activities exhibited by the combination of $A$. vera, tea tree oil, and propolis are of great importance. This research may have a major impact on public health, by providing useful tips to optimize the therapeutic use of some natural drugs. Increase in drug resistance and the limited involvement of the big pharmaceutical industries in the development of new drugs are pushing to new treatments based on ease of prescription and low cost, as well as the idea of an optimal relationship with the environment. Although the three extracts are effective for the topical treatment of bacterial infections, the true limit for future use as antibiotic therapy is given by oral bioavailability. In fact, it is currently unknown whether these products can be absorbed and can manifest systemic antibiotic activity following an oral administration.

\section{Conclusion}

The increasingly growing antibiotic resistance of dermoepidermal strains that cause acne is very often difficult to eradicate, and the available synthetic drugs are starting to become less effective. In this study, it has been shown that the cream containing propolis, tea tree oil, and $A$. vera is more effective in reducing acne compared to the preparation of synthetic origin such as erythromycin. In addition, the preparation based on natural product has been shown to have greater function in reducing erythema. Further studies are highly recommended using larger number of patients with a more extended experimental period. 


\section{Disclosure}

The authors report no conflicts of interest in this work.

\section{References}

1. Williams HC, Dellavalle RP, Garner S. Acne vulgaris. Lancet. 2012;379(9813):361-372.

2. Koo EB, Petersen TD, Kimball AB. Meta-analysis comparing efficacy of antibiotics versus oral contraceptives in acne vulgaris. $J$ Am Acad Dermatol. 2014;71(3):450-459.

3. Bek-Thomsen M, Lomholt HB, Kilian M. Acne is not associated with yet-uncultured bacteria. J Clin Microbiol. 2008;46(10):3355-3360.

4. Contassot E, French LE. New insights into acne pathogenesis: propionibacterium acnes activates the inflammasome. $J$ Invest Dermatol. 2014;134(2):310-313.

5. Krautheim A, Gollnick HP. Acne: topical treatment. Clin Dermatol. 2004;22(5):398-407.

6. Ross JI, Snelling AM, Carnegie E, et al. Antibiotic-resistant acne: lessons from Europe. Br J Dermatol. 2003;148(3):467-478.

7. Humphrey S. Antibiotic resistance in acne treatment. Skin Therapy Lett. 2012;17(9):1-3.

8. Cunliffe W, Gollnick HPM, Gollnick HP. Topical Therapy. In: Cunliffe W, Gollnick HP, editors. Acne diagnosis and management. USA: Martin Dunitz Press; 2001:107-114.

9. Coates P, Vyakrnam S, Eady EA, Jones CE, Cove JH, Cunliffe WJ. Prevalence of antibiotic-resistant propionibacteria on the skin of acne patients: 10-year surveillance data and snapshot distribution study. $\mathrm{Br}$ J Dermatol. 2002;146(5):840-848.

10. Eady EA, Gloor M, Leyden JJ. Propionibacterium acnes resistance: a worldwide problem. Dermatology. 2003;206(1):54-56.

11. Bassett IB, Pannowitz DL, Barnetson RS. A comparative study of teatree oil versus benzoylperoxide in the treatment of acne. Med J Aust. 1990;153(8):455-458.

12. Lalla JK, Nandedkar SY, Paranjape MH, Talreja NB. Clinical trials of ayurvedic formulations in the treatment of acne vulgaris. J Ethnopharmacol. 2001;78(1):99-102.

13. Orafidiya LO, Agbani EO, Oyedele AO, Babalola OO, Onayemi O. Preliminary clinical tests on topical preparations of Ocimum gratissimum Linn leaf essential oil for the treatment of acne vulgaris. Clin Drug Investig. 2002;22(5):313-319.

14. Yoo J, Park S, Hwang I. A clinical study on the effect of a cream containing Ramulus mori extract and tea tree oil on acne vulgaris and aerobic skin flora. Korean J Dermatol. 2003;41:1136-1141.

15. Orafidiya L, Agbani EO, Oyedele AO, Babalolab OO, Onayemic O, Aiyeduna FF. The effect of Aloe vera gel on the anti-acne properties of the essential oil of Ocimum gratissimum Linn leaf - a preliminary clinical investigation. Int J Aromather. 2004;14(1):15-21.

16. Enshaieh S, Jooya A, Siadat AH, Iraji F. The efficacy of 5\% topical tea tree oil gel in mild to moderate acne vulgaris: a randomized, doubleblind placebo-controlled study. Indian J Dermatol Venereol Leprol. 2007;73(1):22-25

17. Balambal R, Thiruvengadam KV, Kameswarant L, Janaki VR, Thambiah AS. Ocimum basilicum in acne vulgaris a controlled comparison with a standard regime. J Assoc Physicians India. 1985;33(8):507-508.
18. Sharquie KE, Noaimi AA, Al-Salih MM. Topical therapy of acne vulgaris using $2 \%$ tea lotion in comparison with $5 \%$ zinc sulphate solution. Saudi Med J. 2008;29(12):1757-1761.

19. Kim B, Shin S. Antimicrobial and improvement effects of tea tree and lavender oils on acne lesions. J Convergence Inf Technol. 2013;8:339-345.

20. Kwon HH, Yoon JY, Park SY, Min S, Suh DH. Comparison of clinical and histological effects between lactobacillus-fermented Chamaecyparis obtusa and tea tree oil for the treatment of acne: an eight-week double-blind randomized controlled split-face study. Dermatology. 2014;229(2):102-109.

21. Grange JM, Davey RW. Antibacterial properties of propolis (bee glue). J R Soc Med. 1990;83(3):159-160.

22. Scazzocchio F, D’Auria FD, Alessandrini D, Pantanella F. Multifactorial aspects of antimicrobial activity of propolis. Microbiol Res. 2006;161(4):327-333.

23. Fernandes Júnior A, Balestrin EC, Betoni JE, Orsi RO, da Cunha ML, Montelli AC. Propolis: anti-Staphylococcus aureus activity and synergism with antimicrobial drugs. Mem Inst Oswaldo Cruz. 2005;100(5):563-566.

24. Drago L, Mombelli B, de Vecchi E, Fassina MC, Tocalli L, Gismondo MR. In vitro antimicrobial activity of propolis dry extract. JChemother. 2000;12(5):390-395.

25. Martinotti S, Ranzato E. Propolis: a new frontier for wound healing? Burns Trauma. 2015;3:9.

26. Menniti-Ippolito F, Mazzanti G, Vitalone A, Firenzuoli F, Santuccio C. Surveillance of suspected adverse reactions to natural health products: the case of propolis. Drug Saf. 2008;31(5):419-423.

27. Sharifi-Rad J, Salehi B, Varoni EM, et al. Plants of the Melaleuca Genus as Antimicrobial Agents: From Farm to Pharmacy. Phytother Res. 2017;31(10):1475-1494.

28. Yadav N, Singhm A, Chatterjeem A, Belemkarm S. Evaluation of efficacy and safetyof Perfact face gel and Perfact face tablets in management of acne. Clin Exp Dematol Res. 2011;2:118.

29. Raman A, Weir U, Bloomfield SF. Antimicrobial effects of tea-tree oil and its major components on Staphylococcus aureus, Staph. epidermidis and Propionibacterium acnes. Lett Appl Microbiol. 1995;21(4):242-245.

30. Carson CF, Hammer KA, Riley TV. Melaleuca alternifolia (Tea Tree) oil: a review of antimicrobial and other medicinal properties. Clin Microbiol Rev. 2006;19(1):50-62.

31. Hajheydari Z, Saeedi M, Morteza-Semnani K, Soltani A. Effect of Aloe vera topical gel combined with tretinoin in treatment of mild and moderate acne vulgaris: a randomized, double-blind, prospective trial. J Dermatolog Treat. 2014;25(2):123-129.

32. Austin BA, Fleischer AB. The extinction of topical erythromycin therapy for acne vulgaris and concern for the future of topical clindamycin. $J$ Dermatolog Treat. 2017;28(2):145-148.

33. Liu J, Ando R, Shimizu K, et al. Steroid $5 \alpha$-reductase inhibitory activity of condensed tannins from woody plants. J Wood Sci. 2008;54(1): $68-75$.

34. Toreti VC, Sato HH, Pastore GM, Park YK. Recent progress of propolis for its biological and chemical compositions and its botanical origin. Evid Based Complement Alternat Med. 2013;2013:1-13.

35. Jain A, Basal E. Inhibition of Propionibacterium acnes-induced mediators of inflammation by Indian herbs. Phytomedicine. 2003;10(1):34-38.
Clinical Pharmacology: Advances and Applications

\section{Publish your work in this journal}

Clinical Pharmacology: Advances and Applications is an international, peer-reviewed, open access journal publishing original research, reports, reviews and commentaries on all areas of drug experience in humans. The manuscript management system is completely online and includes a very quick and fair peer-review system, which is all easy to use.

\section{Dovepress}

Visit http://www.dovepress.com/testimonials.php to read real quotes from published authors. 